\title{
A STUDY ON EVALUATION OF THE EFFICACY OF LAMOTRIGINE AS ADD-ON TREATMENT IN RESISTANT TYPE OF PRIMARILY GENERALIZED TONIC-CLONIC EPILEPSY IN BURDWAN MEDICAL COLLEGE, WEST BENGAL, INDIA
}

\author{
*BandyopadhyayDebasis
}

DrDebasisBandyopadhyay, Associate Professor, Department Of Pharmacology, Burdwan Medical College, West Bengal, India-713104

*Email Id of the Corresponding Author: drdebasisbandyopadhyay@yahoo.in, Mobile No.09474786492

\begin{abstract}
Background: Treatment of resistant type of Primarily Generalized Tonic-Clonic (PGTC) Epilepsy is a difficult area. In different parts of the world lots of studies conducted on this area with varying results. In this perspective, there was need of this study, especially in this part of the country, Burdwan Medical College, West Bengal, India, where previously there was no such study.

Objective: The objective of my study was to evaluate the efficacy of Lamotrigine as Add-On Treatment in Primarily Generalized Tonic-Clonic Epilepsy.

Materials And Methods: 46 resistant type of PrimarilyGeneralized Tonic-Clonic Epileptic patients were randomly recruited from the Out Patient Department (OPD), Burdwan Medical College\& Hospital, West Bengal. The patients were taking either Valproic acid or Carbamazepine or combination of Valproic acid \& Carbamazepine. All were placed on oral Lamotrigine in addition to their exiting antiepileptic drugs. Efficacy was measured subsequently by efficacy measuring scale.

Results: After add-on Lamotrigine 50\% responder rate was $39.129 \%$. 5 patients $(10.869 \%)$ rendered seizure free. The reduction of mean seizure frequency was $47.129 \%$ and response ratio was $-0.32 \pm 0.249$ (mean $\pm \mathrm{SD}$ ). Add-on lamotrigine cause significant reduction $(\mathrm{p}<0.05$ ) of seizure frequency from the baseline value and desirable effects were seen irrespective of patients whether taking valproic acid or carbamazepine or combination of valproic acid\& carbamazepine. Conclusion: Add-on lamotrigine was efficacious in resistant type of Primarily Generalized Tonic- Clonic Epilepsy, in this tertiary care teaching hospital.
\end{abstract}

Key Words: Epilepsy, Primarily, Generalized, Tonic-Clonic, Resistant

\section{INTRODUCTION}

Epilepsy is as old as mankind.About 3000 years ago, it was fully described in Akkadian, the oldest written language. It was written in Mesopotamia (now in Iraq). Other ancient case histories were found in Egypt from 1600 B.C., in China from 1700 B.C. and in India from 1000 B.C. ${ }^{1}$ The word 'epilepsy' is derived from the Greek

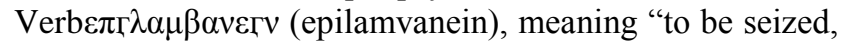
to be taken hold of, or to be attacked", epilepsy was considered to be the "sacred disease", and by the $5^{\text {th }}$ century B.C. the word had gradually acquired the specific and particular meaning associated with it today ${ }^{2}$ and understanding of epilepsy began with the first known book on Epilepsy, " The Sacred Disease", by the a number of many physician of the Hippocratic School, Hippocrates-the Greek Physician, known as "Father of Medicine". 1 But modern concept of epilepsy originate in the work of physicians and scientists of mid- $19^{\text {th }}$ century, the most important among them being John Hughlings Jackson (1835-1911), the "Father of Neurology". ${ }^{2}$ Epilepsy is a group of neurologic conditions, the common and fundamental characteristic of which is recurrent, usually unprovoked epileptic seizures, which result from excessive, synchronous, abnormal firing of neurons of the cerebral cortex. ${ }^{3}$

Markand, ${ }^{4}$ on long term follow up identifies three subgroups of epileptic patients, - (i)about $60 \%$ of the patient either remit after a short period or become easily controlled by antiepileptic drugs and may eventually remit. (ii) $20 \%$ of patients develop chronic epilepsy which is partially responsive to drugs but the patients continue to have scattered recurrent seizures. (iii) The remaining 20\% have a chronic disorder, unresponsive to conventional antiepileptic drugslike Phenytoin, Phenobarbitone, Primidone, Ethosuximide, Valproic acid, carbamazepine, as monotherapy. And these last two groups i.e. $20 \%-40 \%$ are usually treated with polytherapy.

Duncan et $\mathrm{al}^{5}$, , observed that about $80 \%$ of patients developing seizure disorders will achieve the best control with a single drug. For the remainder, add-on another therapy provides improved seizure control. And there is $10 \%-15 \%$ chance of duo therapy controlling seizures when monotherapyhas been unsuccessful. ${ }^{6,7,8}$

Add-on therapy is not synonymous with adjunctive therapy as adjunctive therapy means measure other than antiepileptic drugs or surgical, e.g. education, stress management, provision of support for both patient and family. ${ }^{9}$ Add-on therapy is therapy which is added to the existing drugs.

Lamotrigine is an antiepileptic drug of phenyltriazine derivative. It acts by inhibiting excess release of excitatory neurotransmitter glutamic acid ${ }^{10}$ and prolonging the inactivated state of voltage-gated sodium channel. ${ }^{11}$ It was introduced for add-on treatment for partial seizure in Europe in 1991, and in the USA in $1994 .^{12}$ It is used as monotherapy in patients with partial and idiopathic generalized tonic-clonic epilepsy and offers similar efficacy as traditional antiepileptic drugs like phenytoin, carbamazepine. $^{13,} 14$ Lamotrigine was used as add-on therapy in resistant idiopathic generalized toic- 
clonicepilepsy ${ }^{12,15}$ and also resistant partial epilepsy. But the previous different studies having varying results. ${ }^{16,17}$

In this scenario, there was need of further study especially in this area of the country Burdwan Medical College, West Bengal, India, where previously no such studies with lamotrigine, conducted on the resistant type of primarily generalized tonic-clonic epilepsy.

\section{MATERIALS AND METHODS}

This study was conducted among 46 patients having resistant type of primarily generalized tonic-clonic epilepsy. Patients were recruited randomly from the out patients clinic of the Burdwan Medical College\& Hospital during the March 2006 to February2007. The study was approved by the institutional ethical committee and valid written consent was taken from each patients.

Inclusion criteria: Epileptic patients remaining uncontrolled despite the daily use of either valproic acid or carbamazepine or combination of valproic acid \& carbamazepine, at maximally clinically tolerated doses and continuing seizure with an average frequency at least one seizure per month for the period of at least two years. They comprised a group of medically resistant epileptic patients according to many scientists. ${ }^{18,19,20,}{ }^{21}$ Patients of both sexes were included in my study, ranges of age were between 5.3 years to 40.3 years.

Exclusion criteria: Pregnant patients, alcoholic patients, patients with liver disease, kidney disease, mental disease, patients with mesial sclerosis and below 5 years of age, were not included in my study.

Study design: My study was uncontrolled, unblinded and open level study for one year and the patients were followed up accordingly.
Statistical analysis:All the collected data were analyzed with the descriptive statistics by using the Statistical Package for the Social Science (SPSS) ver-16in Windows-7. Wilcoxon signed rank test was used for comparing the baseline seizure frequency and seizure frequency after add-on lamotrigine ( $\mathrm{p}$ value $<0.05$ was considered statically significant). But frequency analysis was done by manually.

In my study as patients were taking either valproic acid or carbamazepine as monotherapy or combination of valproic acid\& carbamazepine, so after add-on lamotrigine, there were three groups of patients , $1^{\text {st }}$ group - valproic acid\&lamotrigine, $\quad 2^{\text {nd }} \quad$ group carbamazepine\&lamotrigine, $3^{\text {rd }}$ group -valproic acid\& carbamazepine \&lamotrigine.Lamotrigine was added as $3 \mathrm{mg} / \mathrm{kg}$ body weight in children taking valproic acid and 6 $\mathrm{mg} / \mathrm{kg}$ body weight in not taking valproate. In adults it was administered as $200 \mathrm{mg}-400 \mathrm{mg} /$ day. In both cases doses were gradually escalated. After add-on lamotrigine efficacy were measured according to efficacy measuring scale as $\%$ of reduction of seizure frequency from baseline, $\%$ of patients showed $50 \%$ or more reduction of seizure frequency and $\%$ of patients rendered seizure free.

\section{RESULTS AND ANALYSIS}

Total numbers of patients recruited in my study were 46 as randomly. Among them male were 26 (56.521\%) and female were $20(43.478 \%)$. Age range was 5.3 years to 40.3 years, mean age was $17.76 \pm 8.09$ (mean \pm SD). Age $\&$ sex distribution of the patients are shown in Figure No1 and in Table No 1:

Children, adolescents and young adults were the main bulk of my study population of patients.

\begin{tabular}{|c|c|c|c|c|c|c|}
\hline \multirow{3}{*}{$\begin{array}{l}\text { Table No 1: } \\
\text { Age Range }\end{array}$} & \multicolumn{6}{|c|}{ Age and sex distribution of patients } \\
\hline & \multicolumn{2}{|r|}{ Male } & \multicolumn{2}{|r|}{ Female } & \multicolumn{2}{|r|}{ Total } \\
\hline & No. & $\%$ & No. & $\%$ & No. & $\%$ \\
\hline 5 years - 10 years & 5 & $83.33 \%$ & 1 & $16.66 \%$ & 6 & $13.04 \%$ \\
\hline 11 years - 20 years & 10 & $47.61 \%$ & 11 & $52.38 \%$ & 21 & $45.65 \%$ \\
\hline 21 years - 30 years & 8 & $50.00 \%$ & 8 & $\mathbf{5 0 . 0 0 \%}$ & 16 & $34.78 \%$ \\
\hline 31 years - 40 years & 2 & $100.00 \%$ & $\mathbf{0}$ & $0 \%$ & 2 & $4.35 \%$ \\
\hline Above 40 years & 1 & $100.00 \%$ & $\mathbf{0}$ & $0 \%$ & 1 & $2.17 \%$ \\
\hline
\end{tabular}

Distribution of patients according to age of onset of seizure, are shown in Table No 2 and in Figure No 2 . $30.434 \%$ of my study patients whose age of onset were 5 years or less than 5 years, and $34.78 \%$ of patients whose age of onset of seizure were between 11 years to 15 years.

\begin{tabular}{|l|l|l|l|l|}
\hline Table No. 2 & \multicolumn{4}{|l|}{ Distribution of Patients according to the age of onset of seizure } \\
\hline Age of onset of seizure & Male & Female & Total & $\%$ \\
\hline 5 5 years & 7 & 7 & 14 & $30.43 \%$ \\
\hline 6 years to 10 years & 7 & 5 & 12 & $26.09 \%$ \\
\hline 11 years to 15 years & 9 & 7 & 16 & $34.78 \%$ \\
\hline 16 years to 20 years & 2 & 1 & 3 & $6.52 \%$ \\
\hline 21 years to 25 years & 1 & 0 & 1 & $2.17 \%$ \\
\hline Total & 26 & 20 & 46 & \\
\hline
\end{tabular}



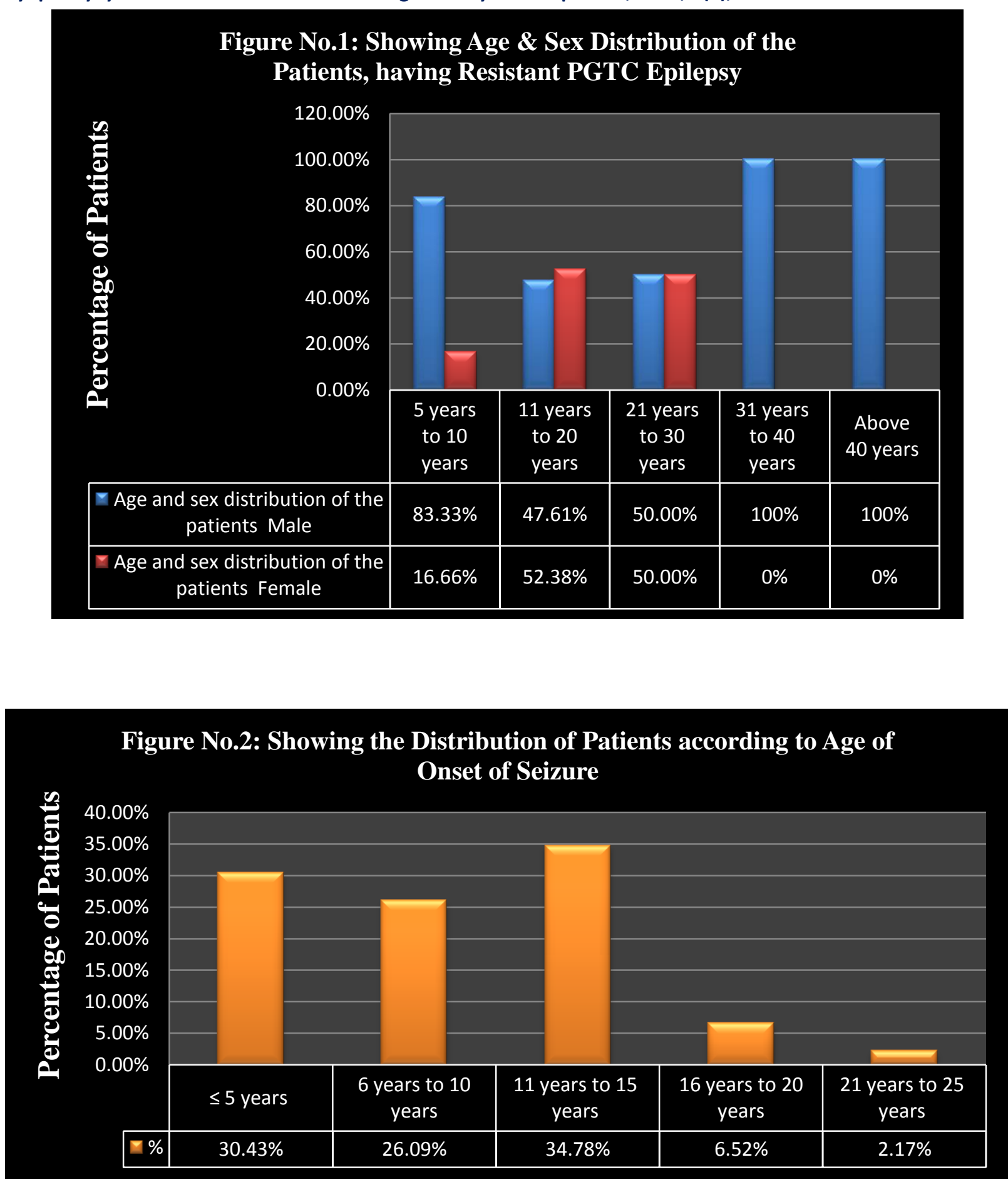

In Figure No. 3 and in Table No. 3 Distribution of patients according to duration of seizure are shown.

\begin{tabular}{|l|l|l|l|l|}
\hline Table No. 3 & \multicolumn{4}{|l|}{ Distribution of Patients According to duration of Seizure } \\
\hline Duration of Seizure in years & Male & Female & Total & $\%$ \\
\hline 5 5 years & 8 & 6 & 14 & $30.43 \%$ \\
\hline 6 years to 10 years & 15 & 10 & 25 & $54.35 \%$ \\
\hline 11 years to 15 years & 2 & 4 & 6 & $13.04 \%$ \\
\hline 16 years to 20 years & 1 & 0 & 1 & $2.17 \%$ \\
\hline Total & 26 & 20 & 46 & \\
\hline
\end{tabular}




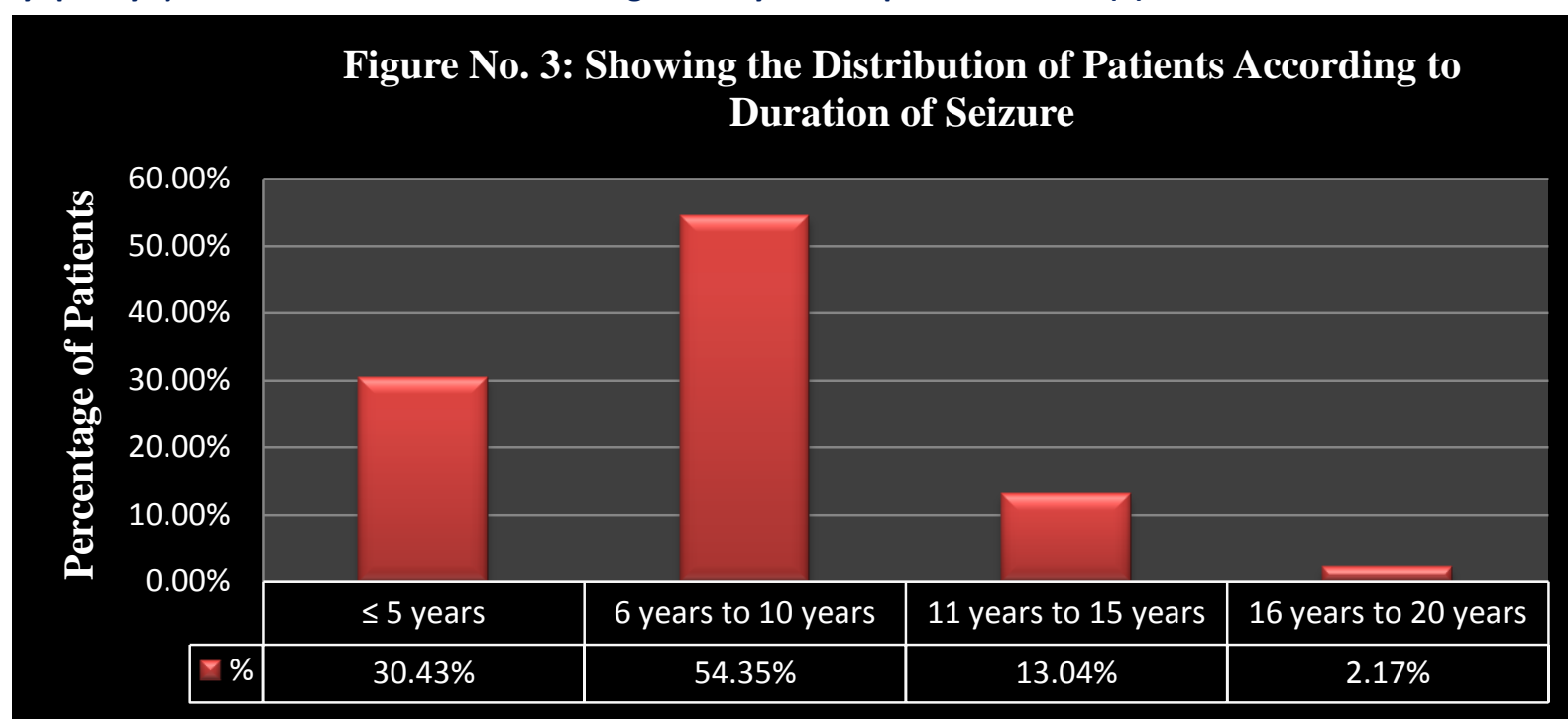

Duration of seizure was calculated as substraction of the age of onset of seizure from the present age of the patient. Mean duration of seizure was $7.98 \pm 3.95$ (Mean \pm SD) years.

Distributions of patients according to different drug groups are shown in Table No. 4 and in Figure No.
4.Before add-on Lamotrigine, the patients either were taking Valproic acid or Carbamazepine or the combination of these two. After add-on Lamotrigine three drug groups produced. Maximum $43.48 \%$ of patients were belonging to the first group.

\begin{tabular}{|l|l|l|}
\hline Table No. 4 & Distribution of Patients according to Different Drug Group \\
\hline Drugs & No. of Patients & $\%$ \\
\hline Valproic acid\&Lamotrigine & 20 & $\mathbf{4 3 . 4 8 \%}$ \\
\hline Carbamazepine \&Lamotrigine & 12 & $\mathbf{2 6 . 0 9 \%}$ \\
\hline Valproic acid \&Carbamazepine\&Lamotrigine & 14 & $\mathbf{3 0 . 4 3 \%}$ \\
\hline
\end{tabular}

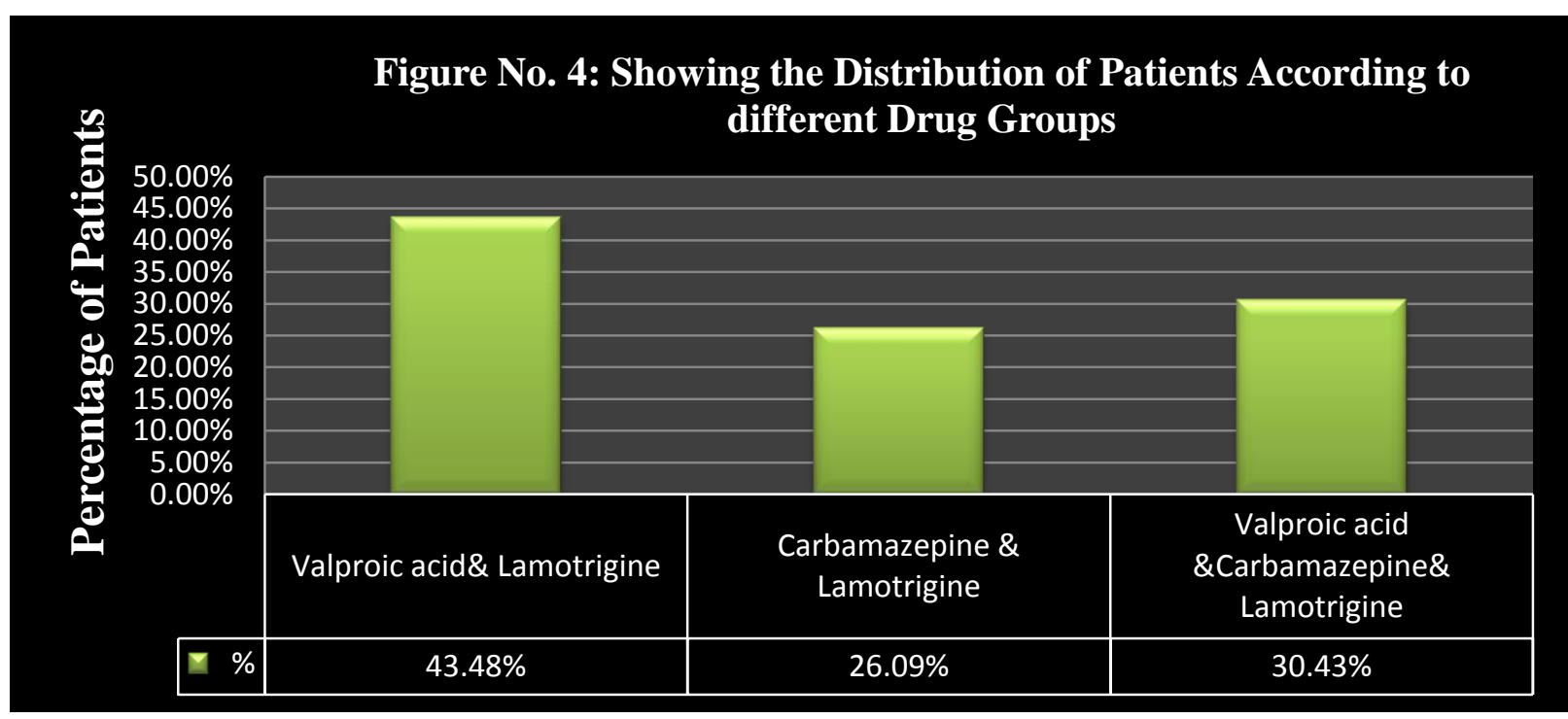

After add-on Lamotrigine it was seen that $10.869 \%$ of patients ( 5 patients) showed no reduction of seizure frequency from the base line value. In the rest of the patients there was reduction of seizure frequency, some showed $100 \%$ reduction, $\leq$ $50 \%$ reduction, $\geq 50 \%$ reduction but $<100 \%$ reduction. Details distributions of reduction of seizure frequency after add-on Lamotrigine are shown in Table No.5 and in Figure No. 5.

\begin{tabular}{|c|c|c|}
\hline Table No. 5 & \multicolumn{2}{|c|}{ Distribution of Patients according to Reduction of Seizure frequency } \\
\hline \% of Reduction of Seizure Frequency & No. of Patients & $\%$ \\
\hline $\mathbf{0 \%}$ & $\mathbf{5}$ & $\mathbf{1 0 . 8 7 \%}$ \\
\hline $100 \%$ & 5 & $\mathbf{1 0 . 8 7 \%}$ \\
\hline$>0 \%$ but $<50 \%$ & 23 & $\mathbf{5 0 \%}$ \\
\hline$\geq 50 \%$ but $<100 \%$ & 13 & $28.26 \%$ \\
\hline
\end{tabular}




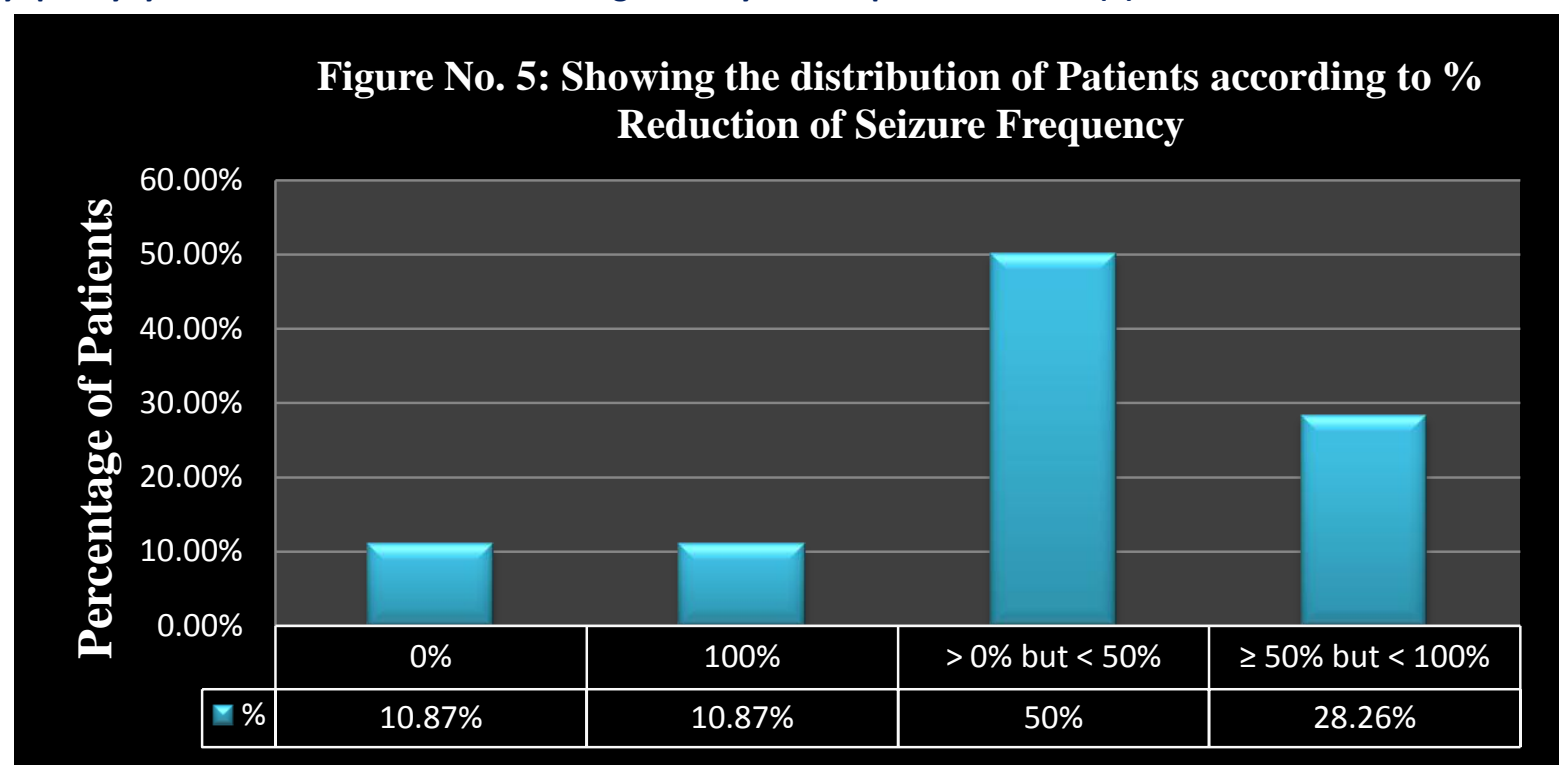

But percentage of reduction of seizure frequency was different in the three groups of patients, taking either Valproic acid \&Lamotrigine, or Carbamazepine \&Lamotrigine or taking combination of Valproic acid \& Carbamazepine \&Lamotrigine.

In the first group total patients were 20 . Out of that $50 \%$ responder rate was $45 \%$ ( 9 patients), and $15 \%$ (3 patients) patients rendered seizure free. In the second group total patients were 12 . Out of that $50 \%$ responder rate was $33.33 \%$ (4 patients) and only $8.33 \%$ (1 patient) rendered seizure free. In the last group total patients were 14 . Out of that $50 \%$ responder rate was $35.71 \%$ (5 patients), and only $7.14 \%$ (1 patient) of patient rendered seizure free. The details distributions of patients showing $\%$ reduction of seizure frequency according to three drug groups are shown in the Table No. 6 and in Figure No. 6.

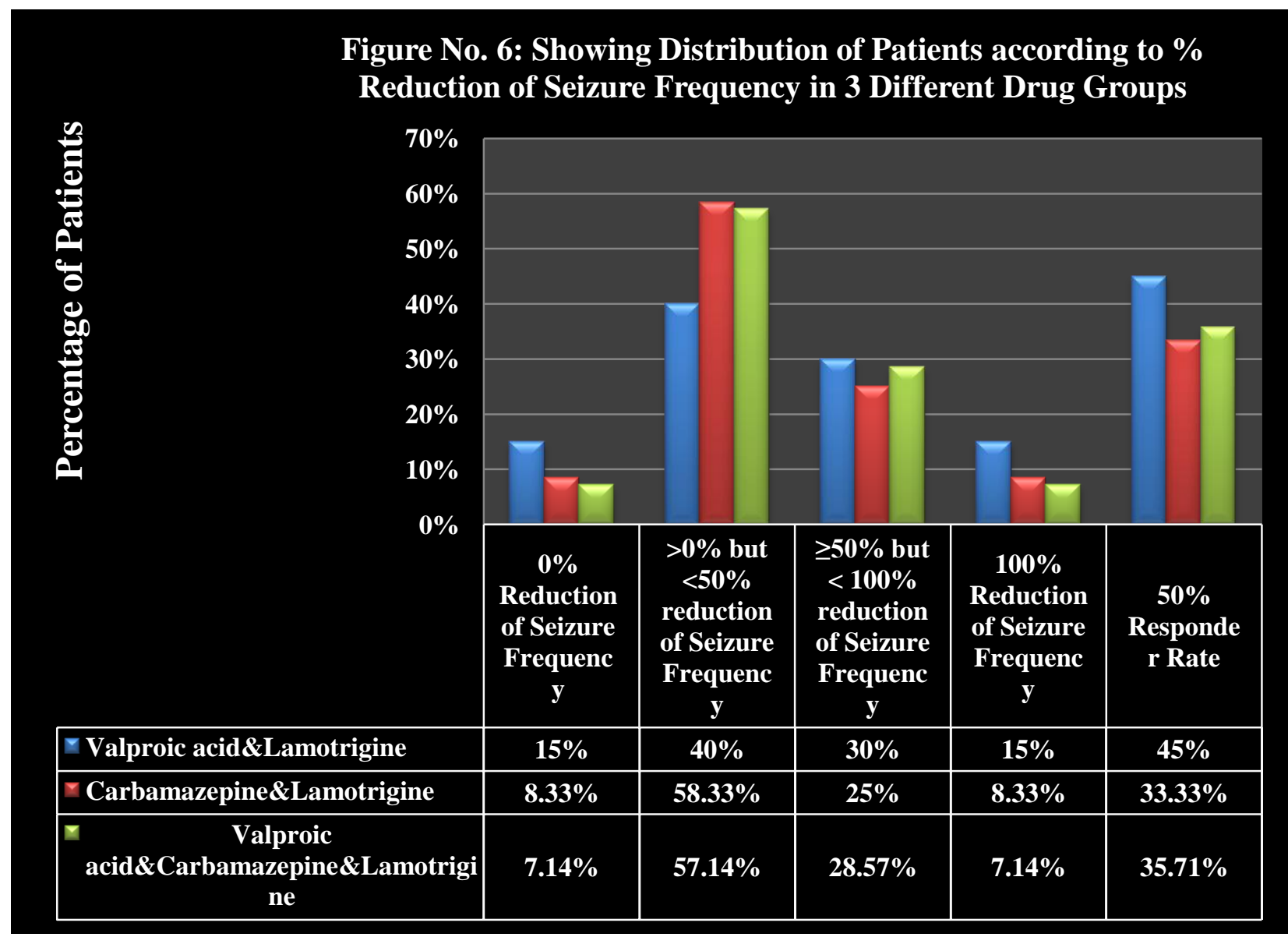




\begin{tabular}{|c|c|c|c|c|c|c|c|c|c|c|c|}
\hline Table No.6 & \multicolumn{11}{|c|}{$\begin{array}{c}\text { Distribution of Patients according to \% Reduction of Seizure Frequency in the } \\
\text { Three Drug Group }\end{array}$} \\
\hline \multirow[t]{3}{*}{ Drug Groups } & \multirow{3}{*}{$\begin{array}{l}\text { No. of } \\
\text { Patient } \\
\text { S } \\
\end{array}$} & \multicolumn{10}{|c|}{ Reduction of Seizure Frequency as \% } \\
\hline & & \multicolumn{2}{|c|}{$\begin{array}{l}0 \% \\
\text { reduction }\end{array}$} & \multicolumn{2}{|c|}{$\begin{array}{l}\text { Above 0\% } \\
\text { but }<50 \%\end{array}$} & \multicolumn{2}{|c|}{$\begin{array}{l}\geq 50 \% \text { but } \\
<100 \%\end{array}$} & \multicolumn{2}{|c|}{$\begin{array}{l}100 \% \\
\text { reduction }\end{array}$} & \multicolumn{2}{|c|}{$\begin{array}{l}\mathbf{5 0 \%} \\
\text { Responder } \\
\text { Rate }\end{array}$} \\
\hline & & No & $\%$ & No & $\%$ & No & $\%$ & No & $\%$ & No & $\%$ \\
\hline Valproic acid\&Lamotrigine & 20 & 3 & $15 \%$ & 8 & $40 \%$ & 6 & $30 \%$ & 3 & $15 \%$ & 9 & $45 \%$ \\
\hline Carbamazepine\&Lamotrigine & 12 & 1 & $\begin{array}{l}8.33 \\
\%\end{array}$ & 7 & $\begin{array}{l}58.33 \\
\%\end{array}$ & 3 & $25 \%$ & 1 & $\begin{array}{l}8.33 \\
\%\end{array}$ & 4 & $\begin{array}{l}33.33 \\
\%\end{array}$ \\
\hline $\begin{array}{l}\text { Valproic } \\
\text { acid\&Carbamazepine\&Lamotr } \\
\text { igine }\end{array}$ & 14 & 1 & $\begin{array}{l}7.14 \\
\%\end{array}$ & 8 & $\begin{array}{l}57.14 \\
\%\end{array}$ & 4 & $\begin{array}{l}28.57 \\
\%\end{array}$ & 1 & $\begin{array}{l}7.14 \\
\%\end{array}$ & 5 & $\begin{array}{l}35.71 \\
\%\end{array}$ \\
\hline
\end{tabular}

But when mean seizure frequency at baseline (per month average) calculated before add-on Lamotrigine, it was 59.39 \pm 31.07 (Mean \pm SD). After add-on Lamotrigine it became $31.29 \pm 26.19$. This was a statistically highly significant reduction $(\mathrm{p}=0.01)$. The percentage reduction was $47.129 \%$. In this study after add-on Lamotrigine to the existing therapy, $10.869 \%$ of patients having resistant type of Primarily Generalized Tonic-Clonic Epilepsy, rendered seizure free and $50 \%$ responder rate was $39,129 \%$. Responder ratio was $-0.32 \pm 0.249$ (mean $\pm \mathrm{SD})$.

\section{DISCUSSION}

Duncan et.al, ${ }^{5}$ observed that about $80 \%$ of patients developing epilepsywill achieve the best control with a single drug. For the remainder, combination therapy provides improved seizure control but there is $10 \%-15 \%$ chance of duo therapy controlling seizure when monotherapyhas been unsuccessful, $6,7,8$. They also reported that about $5 \%$ of patients of resistant epilepsy had their best possible seizure control on the combination of three antiepileptic drugs.

Ferrendelli ${ }^{22}$, stated that a substantial number of patients with epilepsy perhaps as many as $50 \%$ cannot be satisfactorily treated with a single drug and two antiepileptic drugs and sometimes more may be necessary to improve seizure control. In a report of pooled open studies involving 667 adult patients with resistant epilepsy, the overall efficacy, i.e. $50 \%$ responder rate was $32 \%{ }^{10}$, Where as in this my study overall $50 \%$ responder rate was $39.129 \%$. Perucca ${ }^{23}$, on behalf of the study of 105 investigators, published a pooled result of an open-level non blinded multicentricprospective add-on trial of Lamotrigine in adult patients with resistant epilepsy and he reported that $47 \%$ of all patients $(n=338)$ had a reduction in seizure frequency at least $50 \%$ compared to baseline. All most similar type of study was conducted by Brodie et.al ${ }^{24}$, and they found that overall $50 \%$ responder rate was $47 \%$ after add-on Lamotrigine. Matsuo ${ }^{12}$, stated that in uncontrolled study Lamotrigine had shown efficacy as add-on therapy in children and adolescents with resistant multiple seizure type with approximately $40 \%$ of patients showing $50 \%$ responder rate and approximately $10 \%$ of patients rendered seizure free after 3 months of treatment.

Timmings and Richens ${ }^{15}$, found that $79 \%$ of resistant adults with Primarily Generalized Tonic-Clonic Epilepsy achieved 50\% reduction of seizure frequency. Brodie and Yuen ${ }^{25}$, found that add-on Lamotrigine caused $50 \%$ reduction of seizure reduction in $61 \%$ of patients with resistant primarily generalized tonic-clonic epilepsy.

Aicardi and Shorovon ${ }^{26}$, stated that high frequencies of seizures are predictive of difficulties of control. In this my study, patients had also high frequency of seizures. The efficacy of an antiepileptic drug lies in its ability to interrupt or prevent seizures. In this perspective, the results of my study tally with the study of several investigators.

\section{CONCLUSION}

Add-on Lamotrigine to the existing antiepileptic therapy in resistant type of primarily generalized tonic-clonic epilepsy was efficaciousat this tertiary care medical college hospital, in comparison with other studies in different part of the world. 


\section{REFERENCES}

[1] Goldensohn ES. Historical Perspectives. In: Engel J and Pedley TA, editors. Epilepsy: A Comprehensive Test Book. LippincottRaven Publishers, Philadelphia. 1997, p 15-17.

[2] Engel J, Pedley J and TA. Introduction: What is epilepsy. In: Engel J and Pedley TA, editors. Epilepsy: A Comprehensive Test Book. Lippincott-Raven Publishers, Philadelphia. 1997, p 1-7.

[3]Beghi E, Berg AT, Hasuer WA. Treatment of single seizure. In: Engel J and Pedley TA, editors. Epilepsy: A Comprehensive Test Book. Lippincott-Raven Publishers, Philadelphia. 1997, p 128794.

[4] Markand ON. New AEDS. In: Medically Refractory Epilepsy. RadhakrishnanK ,ed, S.C.T.I.M.S. and T. Trivandrum, Kerala. 1999, p 77-92.

[5] Duncan JS, Shorvon SD, Fish DR. Medical Treatment of epilepsy. In: Duncan JS, Shorvon SD, Fish DR, editors. Clinical Epilepsy. Churchill Livingstone, 1995, p 175-238.

[6] Reynolds EA and Shorovon SD. Monotherapy or Polytherapy.Epilepsia, 1981, 22; 1-10.

[7] Schmidt D. Two antiepileptic drugs for intractable epilepsy with complex partial seizure.J.NeurologyNeurosurgery Psychiatry.1982, 45; 1119-1124.

[8] Thompson PJ and Trimble MR. Anticonvulsant drugs and cognitive function. Epilepsia.1982, 23; 531-544.

[9] Homan AW. Adjunctive and combination therapy. In: Engel J and Pedley TA, editors. Epilepsy: A Comprehensive Test Book. Lippincott-Raven Publishers, Philadelphia. 1997, p 1265-1274.

[10] Binne CD. Lamotrigine. In: Engel J and Pedley TA, editors. Epilepsy: A Comprehensive Test Book. Lippincott-Raven Publishers, Philadelphia. 1997, p 1531-1540.

[11] Fitton A and Goa KL. Lamotrigine.An update of its pharmacology and therapeutic use in epilepsy.Drugs. 1995, 50 (4): 691-713.

[12] Matsuo F. Lamotrigine. Epilepsia, 1999, 40(Suppl.-5): S30S36.

[13] BrodieMJ, Richens A, Yuen AWC. Double blind comparison of Lamotrigine and Carbamazepine in newly diagnosed epilepsy. Lancet, 1995, 345: 476-90.

[14] Steiner TJ, Dellaportas CI, Findley LJ, Gross M,et al. Lamotriginemonotherapy in newly diagnosed untreated epilepsy: a double blind comparison with phenytoin. Epilepsia, 1999, 40(5): 601-7.

[15] Timmings PL and Richens A. Lamotrigine in Primary Generalized Epilepsy. Lancet, 1992, 339: 1330-1341.

[16] Schmidt D, Ried S, Rapp P. Add-on treatment with lamotrigine for intractable partial epilepsy. A placebo-controlled crossover trial.Epilepsia, 1993, 34: suppl.-2: 66.

[17]Jawad S, Richen A, Goodwin G et al. Controlled trial of lamotrigine for refractory partial seizure. Epilepsia, 1989,30: 356363.

[18] Berg AT, Levy SR, Novotny EJ, Shinnar S. Predictors of intractable epilepsy in childhood: A case control study, Epilepsia.1996,37 (1): 24-30.

[19] Lowenstein DH. Seizure and Epilepsy. In: Longo DL, Kasper DL, Jameson JL, Fauci AS, Hauser SL, Loscalzo J, editors. Harrison's Principles of InternalMedicine. $18^{\text {th }}$ ed.NewYork: McGrawHill; 2012, vol.2, p 3251-71.

[20] Schmidt D. Medical Intractability in partial epilepsies. In: Luders H, ed. Epilepsy. Raven Press, New York. 1991, p 83-90.

[21] Shorvon SD. Handbook of epilepsy treatment ,Shorvon SD, editor. Blackwell Science Ltd. Oxford. 2000, p 1-225.

[22] Ferrendelli JA. Pharmacology of antiepileptic drug polypharmacy.Epilepsia, 1999, 40 (suppl.-5): S81- S83.

[23]Perucca E. Add on trial of lamotrigine followed by withdrawal of concomitant medication and stabilization on monotherapy. In: Lamotrigine - brighter future. A international congress and symposium series no. 214. LoiseauP,ed. Royal Society of Medicine Press Limited. 1996, p 23-29.

[24] Brodie MJ, Clifford JS, Yuen AWC. Open multicenter trial of lamotrigine in patients with treatment resistant epilepsy withdrawing from add-on to lamotriginemonotherapy .Epilepsia, 1994, 35( Suppl.-7): 69-70.

[25] Brodie MJ and Yuen AWC.Lamotrigine substitution study: evidence for synergism with valproicacid .Epilepsy Res. 1997, 26: 423- 32.

[26] Aicardi J and Shorvon SD. Intractable Epilepsy. In: : Engel J and Pedley TA, editors. Epilepsy: A Comprehensive Test Book. Lippincott-Raven Publishers, Philadelphia. 1997, p 1325-31. 